\title{
ESCRITURA: \\ PALABRA E IMAGEN \\ (Reflexiones sobre la cultura escrita reproducida)
}

\author{
F. M. Gimeno Blay - J. Trenchs Odena \\ Departamento de Paleografía \\ Universidad de Valencia
}

Pocas son las veces que a un paleógrafo se le presenta en una exposición una visión complessiva de la escritura, no toda ella proveniente de la misma área geográfica o del marco escriturario que en los siglos XIV y XV representó la Corona de Aragón y más concretamente la Valencia bajomedieval. Momento complejo, gráficamente hablando, donde se entrecruzaron diversas tendencias escriturarias que procedían de las distintas áreas culturales del occidente medieval europeo (1).

La exposición que durante los meses de noviembre y diciembre (2) ha ocupado el magnífico marco de la Lonja de Valencia, aun sin tener la intención de ser una exposición o muestra antológica de las escrituras utilizadas en nuestras tierras durante los dos siglos que trata, ha conseguido recoger distintas escrituras que nos permiten elaborar unas consideraciones sobre los diversos niveles de uso, difusión y prestigio de las escrituras bajomedievales. Esto supone, indirectamente, interpretar un aspecto más de las sociedades pretéritas al estudiar el alcance que tenía en ellas la cultura escrita, y los comportamientos y actitudes vitales adoptados por quienes no participaron en aquélla y que en algunos casos se vieron condicionados por ella. Análisis que debe partir como primera consideración metodológica de la longue durée, según la expresión de F. Braudel. Efectivamente un estudio limitado a cada una de las piezas reproducidas sólo aportaría un conocimiento concreto de un momento de escritura, que, al mismo tiempo, impediria realizar unas consideraciones de mayor alcance, $y$, 
en definitiva, adentrarnos en ese aspecto tan escasamente estudiado de la historia social que es la cultura escrita.

Alejándose de unas preocupaciones altamente descriptivas, éste es uno de los intereses que anima la investigación llevada a cabo por algunos paleógrafos de nuestra universidad. Partiendo de la consideración de las escrituras en su larga duración, siempre basándonos en un preciso análisis gráfico que no tiene fin en sí mismo, nos adentramos en el estudio de la cultura escrita - tanto en las manifestaciones mayores: la erudita, como las menores: la popular-considerando, en primer lugar, la diversa competencia gráfica adquirida por los litterati de una sociedad concreta, que los testimonios, los momentos de escritura, nos permiten conocer. Por supuesto, también sabemos, que este análisis, el que parte de las formas gráficas, no supondría de ningún modo una comprensión totalizadora de la cultura escrita. Para ello deberíamos estudiar la diversa competencia textual acreditada por las fuentes tomadas en consideración. Ambos análisis preliminares desembocarian, inexorablemente, en un mayor conocimiento de la historia social y por consiguiente de las sociedades pretéritas.

Hemos hablado de escritura y texto. Efectivamente la escritura fosiliza, transmite y hace perenne la palabra, la expresión oral, creando en definitiva el texto. Es una de las formas más perfectas de comunicarse, la escritura, con la colectividad de personas que integran una sociedad. $Y$ ello porque, como afirma J. DERRIDA, l'absence appartient à la structure de toute écriture, y que comentó ampliamente A. d'HAENENS afirmando que l'inscription s'opère en l'absence du destinataire; la lecture, en l'absence du destinateur (3).

Contrariamente la oralité implique la simultanéité, la présence "pleine»; sans support technique, le message oral est néccessairement émis en présence de l'auditeur. L'écriture, elle, comporte deux temps distincts: celui du destinateur, du producteur, du scripteur; et celui du destinataire, du consommateur, du lecteur, ... (4).

La comunicación escrita, la palabra fosilizada, frente a la oralidad, presenta como característica fundamental, un deseo de duración; mediante este útil intelectual se registra algo para que permanezca en el futuro y en una colectividad determinada.

Pero no agotamos aquí nuestra consideración sobre la escritura, también ella es Imagen. Sus simples formas encierran realidades sociales muy particulares y concretas. Recientemente J. E. RUIZ DOMENEC reclamaba la atención sobre este hecho en los siguientes términos: El alfabeto utilizado para describir un fenómeno -...- se llena de cargas emotivas, de imágenes extrasensoriales o de fantasmas individuales (5). Y sucede de esta forma porque su uso, la utilización que se hace de la escritura, supone entrar en contacto más o menos directamente con una forma de concebir las realidades objetivas, o como decia A. d'HAENENS: Pratiquer la relation scripturaire, c'est entrer dans 
un univers, celui du texte et du livre; c'est adhérer à un système de valeurs, celui du discours muet, de l'abstraction, de l'absence, para finalizar con la afirmación de que la relation scripturaire a une dimension imaginaire, symbolique et idéologique (6).

Afirmación que indudablemente nos conduce a otro problema nuevo, el de estudiar la relación, la actividad vital, el comportamiento -en definitiva - de los hombres medievales para con esa nueva dimensión imaginaria y simbólica de la cultura escrita. Problemas metodológicos que introducen a la vieja y empírica ciencia de las escrituras en problemas conexos con la historia de las mentalidades, como pionera en los estudios dedicados al inconsciente colectivo. También ese inconsciente y su contrario, el consciente colectivo, adoptaron actitudes personales y colectivas con respecto a la cultura escrita, inaccesible en general, y en relación a sus plasmaciones concretas en la epigrafía urbana, en las filacterias de los retablos medievales, en la escritura de la cerámica, etc. La presencia pública de la escritura en la sociedad no hacia otra cosa que redistribuir y organizar las distintas realidades vitales. El hombre medieval, ilitteratus o litteratus, siempre pudo localizar tras aquellas escrituras públicas un REFERENTE, pero no un modelo teórico sino más bien un modelo de vida y de organización social que era el suyo propio. Las inscripciones públicas llevaban - sin duda- a representarse mentalmente aquellas jerarquias sociales y más concretamente a las que tenían alguna relación con la cultura escrita.

Como hemos visto hasta ahora la escritura, se nos presenta con un grado polisémico de interpretación, como palabra e imagen, y en consecuencia, intimamente relacionado con el tema propuesto por la exposición Imatge i Paraula. Pero partimos del presupuesto de que la Escritura, en su doble vertiente, no se presenta como algo esotérico, raro y difícil de comprender y cuya consecuencia lógica para el investigador del presente es intentar descifrar su contenido. Su esoterismo, rareza y dificultad de lección, como veremos más adelante, responden al desarrollo de un complejo y concreto programa iconográfico. Pero volvamos a la Escritura, en plano abstracto, y a sus concretas realizaciones: las formas gráficas.

En los últimos años algunos paleógrafos han reclamádo para la Escritura y sus realizaciones el mérito de ser considerada como una fuente histórica. Pero no una fuente sin más, sino un elemento privilegiado para un análisis histórico-social porque:

... ogni epoca ed ogni società possono essere meglio conosciute e valutate dall'uso che fanno dello strumento "scrittura", dal modo in cui provvedono alla distribuzione sociale della 
capacità di scrivere e di leggere, dalla funzione che attribuiscono di volta in volta ai prodotti scritti ed alle loro diverse tipologie (7).

Tal aproximación historiográfica no sólo considera la escritura como el útil comunicativo que está presente en una sociedad de forma pasiva e inerte, sino más bien como el resultado de un complejo de actividades sociales y culturales (8), que ella misma en su plasmación técnica refleja como el resultado privilegiado de una colectividad. A este respecto son elocuentes los interrogantes que se formulaba $\mathrm{K} . \mathrm{H}$. BASSO y que el estudio de la escritura debería resolver. Problemas que afectan a la capacidad de escribir y a su distribución social, a la diferencia informativa transmitida por el canal de la escritura y por la oralidad, a los productores y receptores de la información, a la escritura y promoción social, al aprendizaje, a las operaciones cognoscitivas que se derivan del conocimiento y uso de la misma, y, finalmente, a la función de la escritura dentro del entramado comunicativo de una sociedad (9).

Pero para que esto suceda, es decir, para que la escritura se pueda convertir en un lugar privilegiado deberemos preguntarnos qué hemos de reproducir, qué metodología hemos de seguir al seleccionar los facsímiles, $y$, en definitiva, qué metodología debe guiar nuestra investigación directa sobre las fuentes en los depósitos de información principales: archivos y bibliotecas (10).

La exposición, que comentamos, como no estaba dedicada a la muestra gráfica al no entrar en consideraciones meramente escripturarias se ha introducido en otras cuestiones que si bien no han sido tratadas han quedado reflejadas al exponer los materiales: nos estamos, refiriendo al problema de la transmisión textual a través de la historia. Transmisión unas veces manuscrita y otras impresa (11). A pesar de este nuevo campo de análisis, que en ningún momento puede ser abordado por una exposición, y que demuestra claramente que lo que se ha pretendido en todo momento es reproducir el texto, el contenido, y no las formas gráficas, la exposición permite nuevas consideraciones sobre las diversas formas de ocupación del espacio gráfico teniendo en cuenta el contenido transmitido por cada uno de los manuscritos que tenemos a la vista.

Imagen y palabra sugieren, además, contenidos y formas gráficas o, incluso mejor, a la inversa: de las formas gráficas a los contenidos y a los libros.

LA PALABRA: DE LAS FORMAS GRAFICAS AL LIBRO

El complejo gráfico que aparece en la exposición -a través de 
manuscritos originales y reproducciones - refleja la complejidad social alcanzada desde el renacimiento del siglo XII. Todas las muestras gráficas presentes son el resultado de distintos procesos de aprendizaje, de los distintos componentes de público al que están destinados los libros, y, finalmente, el resultado de la revolución gráfica e intelectual que supuso el renacimiento del siglo XV.

La sociedad medieval, letrada e iletrada, sabia que entre las formas gráficas empleadas existía una jerarquía de prestigio que respondia a una determinada concepción de la vida y a una precisa y concreta organización social.

El análisis de las formas gráficas reproducidas abarca un arco cronológico que iría desde los comienzos del siglo XIV (carta real dirigida a Jaime II, Archivo de la Corona de Aragón) hasta 1735 (fecha de la copia manuscrita de una de las obras de Jaume Roig). La imprenta también dejó su huella en la transmisión textual de alguno de los textos de la literatura valenciana de la época, que también comentaremos aquí.

El arco cronológico considerado recoge dos ciclos de la evolución de la escritura latina: el gótico y el humanístico, tanto en manuscritos como en impresos. Ahora bien no todos los testimonios que acreditan su existencia pertenecieron al área gráfica de la Corona de Aragón por lo que a su redacción o escrituración se refiere: es el caso de la cbastarda» típicamente francesa del Roman de la Rose de Guillaume de Lorris y la «antiqua» empleada en las Opera de Publio Virgilio.

El panorama gráfico se completaría con el uso de las Capitales romanas, de imitación, en el fresco de la Adoración de los Reyes de Nicolau Florentí y en la escalera de subida al coro de la Iglesia Arciprestal de Morella.

Pero analicemos cada uno de los tipos escriturarios, teniendo en cuenta el ambiente social y el público al que estaban destinados los distintos testimonios gráficos.

El primer período escriturario que queda reflejado es el gótico, del que señalaremos varias subdivisiones atendiendo a la antigüedad y al prestigio de los tipos representados. Aludiremos al más antiguo que comúnmente se designa como Textual, en sus dos variantes, FRACTURADA O QUEBRADA, según los distintos tratadistas, y REDONDA (12), caracterizada porque la rotura de las curvas propia de la gótica en general, se ve atenuada por un aspecto redondeado que siempre deja traslucir el quebramiento característico gótico.

Las góticas textuales han constituido, generalmente, el útil por excelencia para la transmisión de la cultura escrita universitaria y eclesiástica medieval, y quizá fuera esa la causa de la duración de estas formas gráficas desde el siglo XII hasta bien entrada la imprenta (13). Se convertirian, de esta forma, en las representantes de la cultura eru- 
dita e intelectual. La exposición nos mostraba estos tipos: en el Llibre Coral del siglo XV de la Catedral de Valencia; en el libro que la Virgen tiene abierto sobre su oratorio en la Anunciación del Maestro de Bonastre y también allí mismo en la filacteria que une las dos tablas mediante «Ave Maria (...) plena dominus tecum»; en el socorrat de Paterna con la leyenda: "Ay amor», en la cual las tres letras finales presentan una caligrafía de referente textual fácilmente reconocible - aunque el instrumento escriturario sea un pincel- $y$, sin embargo, en la parte inicial no se puede discernir tan fácilmente el modelo imitado que puede proceder del campo documental; otras representaciones iconográficas también nos muestran el tipo gótico textual: la danza de la muerte del monasterio de San Francisco de Morella; el INRI del retablo de la Santa Cruz, donde incluso el signo abreviativo y los puntos que aparecen entre las letras son una perfecta imitación de los modelos librarios; y las filacterias —casi imperceptibles en la reproducción- que aparecen en el Retablo de san Miguel del Mestre de Puigmarin en la Catedral de Murcia. La serie de las góticas textuales se finaliza con el missal de santa Eulàlia, el Dotzé del Crestià de F. Eiximenis y el libro del Consolat de Mar (14), representado aqui por una miniatura del mismo.

La relación de muestras que hemos hecho sugiere algunos interrogantes teniendo en cuenta la afirmación hecha de que las textuales estaban ligadas a la cultura universitaria y eclesiástica, y en consecuencia preguntamos por qué emplean este tipo el Dotzé de Eiximenis, el socorrat de Paterna y la dansa de la Mort. La generalización hecha al principio nos obliga a reconsiderar otras posibilidades de utilización de este tipo gráfico. En el caso del Llibre del Consolat se podría explicar su uso porque esta recopilación es un cuerpo de derecho y posiblemente son los destinatarios que encargan la confección material del libro, quienes piden que se utilice este tipo gráfico. Del mismo modo sucederia con el Dotzé del Crestià de F. Eiximenis, cuando la mayoría de los manuscritos de las obras de este autor nos presentan una minúscula cancilleresca o solución bastarda intermedia y local de la bastarda francesa (15).

Otras serian las explicaciones hipotéticas que aclararian el uso de las textuales en el socarrat y en la dansa de la mort, comentarios que reservaremos para el apartado dedicado a la imatge.

La importancia y prestigio alcanzado por este tipo gráfico sobrevivió en el tiempo y ello lo demuestra su utilización en la imprenta (en el incunable del Dotzé del Crestià de 1484; en el Cartoixà de 1495 y todavía en un impreso de Jaume Roig de 1531) y la constitución de sus tipos en modelos a imitar sobre todo para los títulos o parcelaciones de un determinado texto escrito (ms. con poemas de Ausiàs Marc y otros). Su empleo produce un efecto estético que establece una jerarquía gráfica de la página mediante distintos procedimientos: por medio de una ma- 
yor intensidad de tinta en el incunable del Crestià; por medio de letras decoradas o simplemente coloreadas (ms. 17 Bibl. Univ. Barcelona, Antoni CANALS: Scipió e Anibal) o mediante el uso de calderones y figuras similares a la rucha que separa la rúbrica del texto (ms. 991, fol. 120 del Scipió e Anibal, de Antoni CANALS. Biblioteca de Catalunya).

Frente a este compacto y amplio grupo de las textuales aparecen, siempre en el ciclo gótico, la bastarda francesa, como nos lo muestra el Roman de la Rose, y la minúscula cancilleresca italiana, o nuestra solución particular de la Corona de Aragón, particular ejecución causada por la convergencia gráfica aviñonesa de principios del trescientos como muestra el Raonament d'Avinyó de Arnau de Vilanova.

Contrariamente al grupo de las Textuales, la minuscola cancelleresca, nella fase della sua massima espansione (che corrisponde, cronologicamente, al secolo XIV) fu, oltre che scrittura della documentazione privata e pubblica, anche scrittura usuale di notai, giuristi, uomini politici, ecclesiastici, letterati e ceto alto borghese in genere (esclusi mercanti ed artigiani). Divenne perciò anche scrittura libraria, ed in particolare la scrittura per eccellenza di quei testi che non appartenevano né alla cultura eclesiastica, né a quella universitaria (...), cioè di quei testi in volgare... (16).

La participación en la cultura escrita por parte de aquellas personas que no procedían de ambientes universitarios y eclesiásticos originaría el uso de la minúscula cancilleresca o bastarda en campo librario, porque la formación gráfica de todo este amplio grupo, que enumeraba $A$. Petrucci, se afectuaba a partir de la minúscula cancilleresca de uso documental. Conocidos los rudimentos gráficos básicos de la lengua escrita estas formas sólo requerian para ser usadas en el ambiente librario recibir las características propias de la fuente a la que iban destinadas: Ios libros. Giorgio Cencetti las definía como: espaciamiento de las letras, armonia de las dimensiones, regularidad en la alineación, exactitud del trazado, ..., etc. (17).

Ahora bien, aún cuando podamos generalizar el fenómeno a gran parte del occidente europeo, sin embargo cada zona gráfica adoptó su norma, su tipo más o menos canonizado. Los escritorios franceses generaron la Bastarda, como lo demuestra el Roman dé la Rose de Guillaume de Lorris. Escritura que se caracteriza por el acabado en punta de los caídos de las letras $F, P, Q$. $S$ y la inclinación de estas mismas astas hacia la derecha, inclinación que no presentan los manuscritos alemanes con el mismo tipo gráfico. Particular interés reviste en esta escritura la solución adoptada por la de procedencia uncial (18).

El traspaso de la escritura minúscula cancilleresca de campo documental se podia observar al comparar atentamente la carta dirigida a Jaime II (ACA, 4182, Jaime II. Cartes Reials. Repr. panel exposición n. ${ }^{\circ}$ 
2, rep. 1) y la reproducción del folio 30 del Raonament d'Avinyó de Arnau de Vilanova. En ambos casos predomina como caracteristica fundamental el contraste entre el cuerpo pequeño de las letras y a los alzados y caídos de las mismas. Frente a un caja de escritura estrecha, perfectamente alineada, aparecen unos amplios espacios blancos interlineares en los cuales se alojan perfectamente los alzados y caídos prolongados, destacando especialmente el de la "g" minúscula. También se presentan, en algunas letras de alzado, la "banderola" o triángulo que caracteriza a estas escrituras.

La minúscula cancilleresca, en campo librario, hizo fortuna en nuestras tierras y con ella se escribieron muchos de los códices en catalán, obras de creación, traducciones, etc. Deberán exceptuarse, sin embargo todos aquellos casos en los que quien hacia el encargo de copia de un libro exigiera un tipo determinado, como el caso comentado del Dotzé del Crestià de Eiximenis.

Convendría dar un salto geográfico para explicar la presencia en la exposición de manuscritos en Antigua. Nos referimos al manuscrito que contiene las Opera de Publio Virgilio. La escritura documentada por este manuscrito no es una escritura procedente del área peninsular de la Corona de Aragón. Su existencia se debe a la actividad de un grupo de humanistas italianos, que comenzando por F. Petrarca atacaron el esquema gráfico gótico por lo que tenía de incomprensible para ellos. La búsqueda obstinada de manuscritos, que ellos pensaban de época clásica, les llevó a alabar e incluso imitar las grafías de los manuscritos de época carolina designándolas con el calificativo de $A n-$ tiqua. Esto no quiere decir que los escribanos de estas tierras no emplearan este tipo de escritura cuando fueron trasplantados a Italia. Entre otros ejemplos cabe citar a G. Altadell, Bernat Anàt Andòr, Gaspar Peiró, Tomàs d'Olessa y Bertomeu Miquel (19).

No es este el lugar para hacer una valoración del alcance que tuvo la revitalización de la cultura clásica y de la revolución gráfica operada durante el renacimiento italiano ya que otros autores se han preocupado ya de este problema (20). A nosotros nos interesaba este aspecto solamente para situar el comienzo de difusión y consiguiente utilización del segundo ciclo de la escritura latina que antes anunciábamos: la humanistica (21).

La reducción y agrupación de manuscritos en torno a unas nomenclaturas preestablecidas entraña ciertas dificultades porque, como en el caso que tratamos, no sirven para establecer una evolución gráfica ni mucho menos para conocer las herencias escriturarias. El problema es mayor aquí porque la Humanistica, que ha sido estudiada para Italia, Alemania, ..., no ha sido tratada respecto a España y mucho menos para la Corona de Aragón. Ante ello y contando con las reproducciones debemos preguntarnos si la tendencia hacia formas redondeadas en la Corona de Aragón fue una evolución normal que coincidió en el tiempo 
con la efectuada en otros países o si se debieron, más bien, a la imitación de modelos documentales que circularon tempranamente en nuestras tierras. Podemos afirmar con certeza que existía en nuestras tierras un filón semigótico a finales del siglo XIV y durante los primeros años del XV que posiblemente permitiera la rápida adopción de formas próximas a la humanística (22). Ahora bien esa rápida recepción de formas redondeadas y la parcial desaparición de los contrastes de trazos propios de la gótica, no fue óbice para que se mantuvieran algunos elementos de las precedentes bastardas lo cual justificaría hasta cierto punto que casi todas las formas humanisticas empleadas son de referente documental y bien distintas de la antiqua del manuscrito de las Opera de P. Virgilio. Lo cual no sería sino la perpetuación de la situación gráfica anterior y la división que hemos establecido entre texto transmitido y formas gráficas empleadas.

Para finalizar el panorama gráfico descrito hasta este momento sólo nos falta comentar el uso de escrituras capitales en la iconografía. Estas formas gráficas tan sólo están representadas en la orla que enmarca la Adoración de los Reyes de Nicolau Florenti (Museo Catedral de Valencia) y en la escalera del coro de la arciprestal de Morella: «anuntio vobis gaudium» acompañando a la escena de los pastores anunciziıdo el nacimiento de Jesucristo. La presencia de estas escrituras decorativas supone la revitalización de las formas clásicas romanas y el paulatino desplazamiento de las góticas epigráficas. El prestigio alcanzado por las romanas, junto al ambiente renacentista en el que se produce su revitalización son las causas que provocarían la suplantación de las góticas epigráficas.

La combinación escritura y pensamiento conduce definitivamente al texto, $y$, en consecuencia, al documento en forma epistolar, y al libro como productos acabados. Todos los materiales manuscritos expuestos nos han proporcionado también elementos relativos a la forma de ocupación del espacio gráfico o disposición de determinados contenidos, siempre teniendo en cuenta tradiciones escriturarias diversas, funcionalidad de los mismos productos, modalidades de lectura, etc. (23).

Destacan entre todos los manuscritos los que presentan una colección poemática. La forma de impaginazione es el uso de estrofas de ocho versos, separados en dos hemistiquios por medio de una cesura representada por una línea inclinada. Las estrofas están separadas por un espacio blanco interlinear, más o menos equivalente a dos versos. Algunos de los manuscritos incluidos en este grupo presentan en su margen derecho las iniciales de cada verso separadas y decoradas, como el Cançoner de Zaragoza, tímido recuerdo de las utilizadas en el manuscrito del Roman de la Rose. Otros, por el contrario, tan sólo presentan la inicial separada sin ningún tipo de decoración. Esta estructura y disposición del espacio gráfico se rompe cuando es preciso registrar también al autor intelectual de la obra literaria o indicar la 
«tornada», en cuyo caso se utilizan minúsculas agrandadas de referente gótico textual.

Distinta es la forma de ocupación gráfica en el Dotzé del Crestià, a doble columna; en el Coral, con la miniatura de San Esteban, de la Catedral de Valencia, de grandes dimensiones condicionadas por una lectura comunitaria; o en las Opera, de P. Virgilio, el Raonament d'Avinyó de Arnau de Vilanova, el Scipió e Anibal de Antoni Canals, que se presentan a línea tirada.

El resultado final será la presencia de la escritura (en sus formas realizadas) y del libro como imágenes y símbolos culturales privilegiados en la vida urbana de la Valencia de los siglos XIV y XV, y nos atreveriamos incluso a afirmar del Occidente bajo-medieval (24).

\section{LA IMAGEN: REPRESENTACION Y SIMBOLISMO}

“Per comprendere il valore di un' iscrizione nella società antica -e soprattutto in quella romana- bisogna scoprire $i$ sentimenti e i significati, consapevoli e inconsci, che la scrittura suscitò sia in chi la sapeva leggere sia in chi la considerava senza compitarla, dai tempi della prima alfabetizzazione sino alla tarda antichità̀ (25).

La afirmación propuesta por G. C. SUSINI con respecto a la escritura pública en el mundo romano es muy interesante para el aspecto que queremos tratar en este apartado. Para comprender la "IMATGE" que pudo representar la escritura en la baja edad media es preciso, en primer lugar, descubrir - como afirma Susini-los sentimientos y significados que la sociedad medieval atribuía a la escritura. Detrás de cualquier representación de la cultura escrita siempre encontramos el mismo referente: una sociedad cristiana en la que el grupo de los "Oratores" aparecía socialmente diferenciado.

También la exposición que hemos comentado a lo largo del presente trabajo, ha tratado de forma indirecta la situación de la IMATGE de la cultura escrita. Son muchos los retablos medievales que nos presentan el libro o la simple escritura. Creemos oportuno, antes de introducirnos en el análisis funcional e interpretativo de estos programas iconográficos, estudiar cuáles fueron los tipos gráficos representados en la baja edad media valenciana, a tenor de las pinturas reproducidas.

En un nivel descriptivo comentariamos que la cultura escrita se halla representada en dos niveles: la escritura -el texto recordatorio-y el libro. Por lo que respecta a la primera nos encontramos siempre con las escrituras gótico-textuales, excepto en el caso de los productos artísticos tardíos —de la segunda mitad del siglo XV — que representan la revitalización de las formas clásicas romanas (escaleras del coro de 
Morella; cenefa de la Adoración de los reyes de Nicolau Florenti y, finalmente, el ribete con capiteles que presenta el manto de la Virgen en la Anunciación del Maestro de Bonastre). La conjunción de ambas en un mismo espacio pictórico-comunicativo (especialmente en la Anunciación del Maestro de Bonastre) deja traslucir una situación confusa de multigrafismo relativo, donde la imitación de capitales de impronta romana comienzan a desplazar y ocupar el espacio gráfico de representación que durante la baja edad media había ocupado el alfabeto mayúsculo gótico, tipo gráfico, este último, que se había conseguido gracias al redoblamiento de unos trazos y al recurvamiento de otros sobre bases capitales y unciales (26).

La situación de multigrafismo relativo desorganizado, de un primer momento, que acabará adoptando las formas capitales en inscripciones públicas, se ve acompañado, asimismo, en la representación por un multigrafismo absoluto, como lo evidencia uno de los paneles del Retablo de St. Esteve del siglo XIV, donde aparecen unos libros abiertos escritos en hebreo (?). La iluminación que el Espiritu Santo ejerce sobre el personaje central lleva a las personas que participan en la escena a destruir los textos escritos en la misma escritura y lengua lo cual supone la afirmación de la cultura latino-cristiana.

Todavía nos proporcionan los retablos medievales algunos detalles sobre el formato de los libros, su encuadernación, etc. De todos ellos, sólo uno se presenta abierto y escrito: concretamente en la Anunciación del Maestro de Bonastre, y siguiendo la jerarquia gráfica bajomedieval su escritura es una gótica textual, que como hemos anunciado anteriormente constituye la escritura por excelencia de la transmisión de la cultura eclesiástica.

Pero, intentemos, ahora, comprender el por qué de todos estos mensajes de la pintura medieval.

Aun a riesgo de caer en una generalización banal podemos afirmar que las pinturas con escrituras y libros se incluyen en una èpoque, según Jean-Claude SCHMITT, où l'Eglise se préoccupe de mieux être comprise des masses qu'elle entreprend de convertir, spécialement dans les villes: il lui fallait annoncer la Vérité du Christ, faire admettre la morale chrétienne -...-, tout en adaptant son prope système de valeurs aux nouvelles données sociales: elle devait reconnaitre enfin le rôle joué par les laisc dans la société (27).

El ambiente descrito por J. C. Schmitt como una de las causas que influirian en un mayor desarrollo de la predicación durante la baja edad media también serviria para explicar la imagen de la cultura escrita, unida a temas religiosos, porque su presencia en cualquier ámbito social -bien sea rural o urbano- se puede interpretar como una forma 
más de predicación: la visión contemplativa y su derivación en el recuerdo. Pero la presencia de la escritura pública en la vida urbana no sólo sería el efecto, o la consecuencia, de una evangelización/alfabetización controlada por parte de la Iglesia. Existieron otros muchos factores que influyeron en la presencia cada vez más importante de la escritura en los ambientes urbanos sobre todo, entre los cuales no hay que olvidar la nueva estructuración urbanistica de las ciudades y un mayor índice de alfabetización entre sus habitantes (28).

Pero debemos descartar el estudio de la epigrafía urbana, de los graffitti, affiches, etc. para centrarnos única y exclusivamente en la escritura de los retablos, porque ella por si misma es capaz de permitirnos un análisis parcial y concreto, y también porque de esta forma nos mantenemos dentro de los materiales reproducidos en la exposición.

Al principio de este trabajo aludiamos a la relación con la ausencia que supone todo texto escrito siguiendo a J. Derrida. Además de la presencia de la ausencia la escritura también es representación, como decía A. d'Hasnens porque:

L'Écriture alphabétique représente les choses par des signes.

Elle est représentation abstraite et muette, abrégée et miniaturisée (29).

Ambos factores - la ausencia y la representación abstracta, muda y miniaturizada - son fundamentales para la comprensión de la imagen que representó la iconografía de la escritura en la sociedad medieval. La estructura de la ausencia se establece entre el pintor o su taller y el público al que va dirigido. Entre pintor y lector existe una diferencia espacio-temporal que es suplida por la imagen; esta consigue perpetuar a pesar de ese espacio-tiempo un referente concreto y determinado que se materializa en la existencia de un modelo social. Y también aquellas filacterias son representaciones abstractas, abreviadas, porque tan sólo expresan frases memorables, concretas, pasajes bíblicos, etc., que actuarian como acicate de la memoria entre el público alfabetizado y el analfabeto.

Faltaría conocer ahora cómo se transmitía a la colectividad y, en definitiva, cómo actuaria el mensaje sobre la población. De cómo se produjera este fenómeno dependería la actitud de la población a la que se dirigían los textos escritos.

Atendiendo a la clásica división de la sociedad en alfabetizados y analfabetos, creemos que los canales de circulación del mensaje escrito presentaron dos modalidades. Para el alfabetizado, litteratus en general, aquella escritura era símbolo y texto. Como símbolo, la identificó rápidamente con la cultura eclesiástica, porque, según hemos anunciado anteriormente, se materializaban sus textos con las formas textuales. A ello contribuyó el hecho de que esas frases, siempre se presentaban junto a imágenes religiosas. Como texto le sirvió para re- 
cordar situaciones objetivas en las que habia oído predicaciones sobre asuntos parecidos, o en las que él mismo habia leído libros que le presentaban contenidos semejantes, lo cual no es de extrañar porque existen tratados de predicación donde los temas están ordenados alfabéticamente (30). En el caso del Art abreujada de predicació de Ramón Llull (31) es la asignación de unos valores a las letras del alfabeto y su combinación nemotécnica la que permitió a cualquier predicador hablar de un tema determinado según la fiesta o el dia de celebración en el que él debía transmitir unos pensamientos. Todo ello se producía de esta forma porque la Escritura apparait comme un substitutif dégradé de la parole (32) y también porque la escritura se presenta en la religión cristiana comme support de la relation à l'Absolu (33).

El segundo canal al que hacíamos referencia se presentaba cuando el lector-receptor del mensaje era un analfabeto. Para éste el mensaje, las letras, sólo eran un símbolo. Al no entender el lenguaje escrito, su comprensión sólo era posible si intervenía un intermediario cultural, es decir, sólo sería comprensible cuando el intermediario transmitiera con sus comentarios el mensaje contenido en aquel texto. De esta forma la escritura, como sustituto de la palabra, se convertía en palabra y hacía circular el mensaje transmitido por el canal de la oralità-auralità (34). La lectura que el intermediario efectuaba ante el público analfabeto reunido en torno a la escritura producía varios efectos, tal vez inconscientes. Servia para que los analfabetos aprendieran a leer un determinado texto que les proporcionaba el recuerdo de imágenes comunes producidas por la evangelización/alfabetización a la que antes aludiamos. El analfabeto, a diferencia del alfabetizado, no era capaz de identificar por medio de una imagen a la cultura eclesiástica. Su mente, mucho menos relacionada con la cultura escrita, le reproducía situaciones de dominio de ésta sobre su medio de comunicación natural : la oralidad. Le podían recordar, a lo sumo, lugares comunes y realidades subjetivas que a él mismo le habian administrado los predicadores. Sirva de ejemplo el retablo de la Santa Cruz, en el cual el pintor al dibujar sobre la cruz la palabra INAI ha utilizado como signos abreviativos trazos similares a los clavos, que en todo momento ayudarian a reforzar en la mente de los observadores la idea de la Crucifixión. En consecuencia podemos decir que la imagen que produce el símbolo escrito en el analfabeto es difusa y nada concreta. Distinto es el caso de las personas alfabetizadas, las cuales rápidamente adscribian aquellas formas a la cultura escrita eclesiástica.

Pero la representación de la escritura en las sociedades medievales no agota aquí sus posibilidades simbólicas. Las formas gráficas se enmarcan en un todo, en un universo interpretativo más complejo que es el constituido por el libro. El uso de la escritura significa el adhèrer à un système de valeurs, celui du discours muet, de l'abstraction, de l'absence (35) y sobre todo en una sociedad, la bajomedieval, que andava sempre piú organizzando le sue gerarchie secondo paradigmi di 
cultura meramente "testuale» (36) porque esa misma estructura social, y más concretamente la religión cristiana, estaba presidida por el libro por excelencia: la Biblia.

Pero tal vez haya que precisar que el Libro, en épocas de escasa alfabetización se presenta y se interpreta como la verdad absoluta, y como la objetivación máxima alcanzada por el pensamiento humano. Es por tanto el mayor cúmulo de sabiduría y de ciencia (37). En el caso de la Biblia aparece aquí como la expresión máxima de la voluntad divina porque, como afirmaba $\mathrm{S}$. Pablo en su epístola segunda a Timoteo, Toda escritura es inspirada por Dios y útil para enseñar, para argüir y para educar en la justicia... (38). De esta forma la representación iconográfica de la escritura quedaba totalmente justificada, porque la imagen que se desprendía de su visión era siempre la misma, Dios a través de los libros y del grupo de los eclesiásticos a cuyas representaciones acompañaba en algunos casos ya que eran ellos los únicos que tenían la capacidad de interpretar las SAGRADAS ESCRITURAS. EI libro es, según J. FERRANDO ROIG, común a los Apóstoles, Evangelistas, doctores y escritores ec/esiásticos (39).

Sobre la posición en la que aparece, abierto o cerrado, se han dado diferentes interpretaciones. Para unos Un livre fermé signifie la matière vierge. Est-il ouvert, la matière est fécondée. Fermé le livre conserve son secret. Ouvert le contenu est saisi par celui qui le scrute (40). Refiriéndose a las imágenes de los libros reproducidos en las metopas del templo de San Pietro in Montorio a Roma de Donato Bramante, A. Petrucci nos decía:

La contrapposizione tra la forma aperta e quella chiusa richiama antiche tematiche paleocristiane ed altomedievali, ma l'esaltazione del libro come strumento della religione e del pontificato romano sottolinea l'ideologia di un Rinascimento interpretato nella sua prospettiva cristiana e romana (41).

No importa tanto el análisis descriptivo de las formas de representar el libro -abierto o cerrado- como el contenido simbólico que desprende de su presencia. La presencia del libro significa la exaltación y en definitiva la primicia y preeminencia de la cultura escrita -en su manifestación más perfecta- sobre cualquier otro tipo de comunicación para el círculo que crea esta imaginería, teniendo presente que la cultura escrita por excelencia es la eclesiástica, precisamente porque es la que mayor difusión y raigambre ha tenido en las sociedades medievales y también porque, como afirma G. CARDONA, Attraverso la lingua scritta e il medium della scrittura passano, nozioni, credenze, sistemi di pensiero e dottrine religiose, y es precisamente por ello por lo que la posesión, como inteligencia de la cultura escrita, ... concorre a dar un'autorità particolare a chi detiene la scrittura in una società in cui essa non sia un'acquisizione generale (42). De esta forma se explicaria la posición defendida por San Agustín cuando él mismo se presenta 
diciendo: Je suis votre codex, votre écriture (43) y quedaría legitimada y justificada teóricamente la presencia del libro en la sociedad medieval, y siempre entre las manos de los eclesiásticos como únicos intérpretes de los libros religiosos.

En definitiva, este orden jerárquico de los símbolos visivos, que vienen representados por la escritura y el libro, reclama y conduce sensorialmente hacia un conocimiento determinado y concreto que objetivaría el libro: la Biblia y que daría a conocer la Iglesia, a través de la predicación y de la oración y, en consecuencia, a través de la evangelización/alfabetización. Conocimiento e imágenes de realidades subjetivas que en ningún momento puede alcanzar el pueblo si no es a través de la interpretación y consecuente predicación por parte de los Oratores. La comunicación también se establecería aqui de la misma forma que hemos comentado en el caso de las escrituras de los retablos. El canal estaría constituido por las siguientes fases: oralità-scrittura-auralità (44), que S. Agustín justificaba plenamente con la frase citada anteriormente.

La solución a toda la jerarquía visiva y simbólica que hemos comentado hasta aquí podiamos resumirla en: libro-oratores-iglesia. EI libro como el instrumento privilegiado de la religión, en la medida en que es el representante máximo, simbólicamente, de la cultura eclesiástica, pero al mismo tiempo como estructura material, perfecta y acabada, se convierte en el lugar óptimo para la conservación, permanencia y transmisión de unos conocimientos hacia el futuro. Pero en un futuro ilimitado, porque los distintos mecanismos de transmisión, manuscrito e impreso, asegurarán su pervicencia mientras la humanidad exista.

Pero el libro no es solamente el lugar de conservación. También se presenta, en su forma acabada y perfecta, como una forma de recuerdo y de activación de la memoria, de una memoria selectiva que excluye unas realidades sociales al hacer predominar el libro y en consecuencia a la cultura escrita (45). El efecto de memorización se ha conseguido porque el libro -al igual que sucedía con la escritura- es, según A. d'Haenens: excédent et supplément. Será EXCEDENTE porque excède l'espace et le temps de sa production: en fixant l'énoncé verbal sur un support matériel objectif; en le transforment el objet d'échange; en étendant le champ de la communication orale et gestuale, y será SUPLEMENTO en la medida que supplée régulièrement la présence; elle répare et modifie la présence; elle reduit les dimensions de la présence dans son signe (46).

La cualidad de Excedente y Suplemento la adquieren la Escritura y el Libro porque siempre, en definitiva, queda el texto, la realidad objetiva interpretable, que aparece por encima del espacio y de cualquier otro tipo de duración temporal. Nos preguntamos si esta permanencia y el hecho de que siempre se mantenga por encima de todas estas reali- 
dades objetivadas evoque la domination de l'Église sur les dimensions de l'espace et du temps (47), cuestión interesantísima que convendría desarrollar.

\section{EPILOGO}

Limitarnos a esta visión del uso, funcionalidad y difusión de la escritura en la sociedad bajomedieval, sería quedarnos simplemente en comentar el uso institucional de este útil intelectual por excelencia que es la escritura.

Algunos de los aspectos tratados por la exposición quedaron registrados por la escritura: la aventura, el amor, etc. Pero su registro escrito no se debe única y exclusivamente a las personas, digamos cultas de aquella sociedad, sino también a las clases subalternas de la misma que comenzaron a apropiarse durante la baja edad media de la escritura necesaria para gestionar sus propios asuntos. Los mercaderes, tenderos, botiguers, speciers, etc., son elementos importantes a considerar en el estudio del uso social de la escritura.

La consideración, en campo gráfico, de estos amplios sectores comporta siempre un aumento cualitativo para cualquier estudio de la escritura porque también la escritura, como IMATGE i PARAULA, significó para estos aprendices - nuevos alfabetizados - un tabú, un elemento reverenciado y temido, una aspiración en su vida, una necesidad a veces inalcanzable, sabiendo, además, que su inmersión en el círculo de la prestigiosa "Cultura Escrita» podía derivar en un cierto ascenso y promoción social (48). 


\section{NOTAS}

(1) Una exposición de esta situación gráfica, en campo documental, puede consultarse en GIMENO BLAY, F. M., La escritura gótica en el Pais Valenciano después de la conquista del siglo XIII. Valencia, Departamento de Paleografía, 1985; y también en un trabajo nuestro posterior: F. M. GIMENO - J. TRENCHS, La escritura medieval en la Corona de Aragón (1137-1500). "Paleografía III. Curso de Estudios Universitarios Castelló-Benassal, junio 1985" (en prensa), donde se analizan todas las tendencias gráficas que afectaron a la Corona de Aragón durante la baja edad media, tanto en el campo documental como en el librario.

(2) Cfr. Imatge i Paraula als segles XIV - XV. Llotja de València, novembre-desembre, 1985. València, Diputació Provincial, 1985.

(3) Cfr. HAENENS, A. d', Ecrire, utiliser et conserver des textes pendant 1.500 ans: la rélation occidentale à l'écriture. SCAITTURA E CIVILTA, VII (1983), pp. 225-260. La cita está tomada de las pp. 227-228.

(4) Ibidem.

(5) Cfr. RUIZ DOMENEC, J. E., La memoria de los feudales. Barceiona, 1984, p. 16.

(6) Cfr. HAENENS, A. d' Écrire, utiliser et conserver, p. 242.

(7) Cfr. Scrittura e Popolo nella Roma Barocca, 1585-1721. A cura di Armando PETRUCCl. Roma, 1982. La cita está tomada de la introducción explicativa de Petrucci, Questa mostra, p. 9. Recientemente A. BARTOLI LANGELI en la introducción al "convegno" PALEOGRAFIA, DIPLOMATICA, CODICOLOGIA E STORIA SOCIALE, finalizaba su intervención de la siguiente manera:

... ma utilizzare i propi oggetti specifici come privilegiati punti di osservazione per conoscere e far conoscere, capire e far capire una società, l'uomo in società, l'uomo in relazione. Perché lo sono, punti di osservazione privilegiata, e propio le nostre discipline lo hanno dimostrato.

Cfr. BARTOLI LANGELI, A., Introduzione, a "PALEOGRAFIA DIPLOMATICA CODICOLOGIA E STORIA SOCIALE». II Convegno Associazione italiana dei paleografi e diplomatisti. Perugia, 28-30 marzo, 1985. Perugia, 1985, p. 15.

(8) Cfr. la definición de SCRITTURA propuesta por A. BARTOLI LANGELI en Ancora sU paleografie e storia della scrittura: A proposito di un convegno perugino. SCRITTURA E CIVILTA, II (1978) p. 281.

(9) Cfr. K. H. BASSO, The Ethonography of Writing, en «Explorations in the Ethnography of Speaking” ed. por R. BAUMAN y J. SHERZER, Londres 1974, pp. 425-432. El fragmento comentado está sacado de las páginas $431-432$, según CARDONA, G. R. Sull'Etnografia della Scrittura. SCRITTURA E CIVILTA, I (1977), p. 217.

(10) Planteamientos metodológicos parecidos se podrán encontrar en GIMENO BLAY, F. M., La escritura gótica en el País Valenciano, y especialmente en el capítulo titulado "La escrituralidad valenciana bajomedieval: muestras para su estudio", pp. 113-120. 
(11) No es nuestra intención entrar aqui en la consideración de la diversa transmisión textual de las obras de los autores representados en la Exposición. Por eso remitimos a la parte final del catálogo porque en él el lector interesado encontrark obras de referencia que le acercarán a las fuentes de la literatura que estuvo presente en la Imatge i Paraula (Cfr. Imatge i Paraula als seglos XIV - XV, cit).

(12) Cfr. las colecciones de facsímiles siguientes: CROUS, E. - KIRCHNER, J., Die gotischen Schriftarten. Zweite Auflage. Würzburg, Fränkische Gesellschaftsdruckerei, 1970; KIRCHNER, I. Scriptura Gothica Libraria. A saeculo XII usque ad finem medii aevi LXXXVII imaginibus illustrata. Monachii et Vindobonae, in aedibus Rudolfi Oldenbourg, M.DCCCC LXVII; CANELLAS, A., Exempla Scripturarum Latinarum. In usum scholarum. Pars Prior, Editio iterata Caesaraugustae, MDCCCCLXXIIII. Pars A/tera, Caesaraugustae, MDCCCCLXXIIII; y MAZAL, D. Buchkuntst der Gotik. Graz-Austria, Akademische Druck- und Verlagsanstalt, 1975.

(13) Sobre el uso de la escritura gótica en los primeros tiempos de la imprenta cfr. el volumen: Historia de la imprenta hispana. Madrid, Editora Nacional, 1982, y también los facsimiles reproducidos por A. MILLARES CARLO en su Introducción a la historia del libro y de las bibliotecas. México, Fondo de Cultura Económica, 1971.

(14) Las miniaturas de este manuscrito fueron estudiadas por A. VILLALBA DAVALOS, La Miniatura valenciana en los siglos XIV y XV. Valencia, Institución Alfonso el Magnánimo. 1964; cfr. especialmente las reproducciones 22 a 26.

(15) Crr. Biblioteca Universitaria de Valencia, mss. 209, 214 y 576. También CANELLAS reproducia en sus Exempla, Pars Altera un fragmento del ms. Scala Dei de Eiximenis, facsímil $n .^{\circ}$ LIX.

(16) Cfr. PETRUCCI, A., Lezioni di storia della scrittura latina. Corso Istituzionale di Paleografia. Roma, II Bagatto, ristampa 1985; p. 102.

(17) Cfr. CENCETTI, G. Lineamenti di storia della scrittura latina. Bologna, 1954; p. 55.

(18) Sobre la Bastarda deberán consultarse: BAUDIN, F., Les écritures bâtardes. Les Beaux-Arts. Numero spéc. 1959. Recensionado en SCRIPTORIUM, XVII (1963), y también el trabajo de P. SPUNAR: L'évolution et la fonction de la batarde en Bohème et Pologne. STUDIA ZRODLOZNAWCZE. Comentations VI (Warszawa-Poznán, 1961) pp. 1-19. Sobre las distintas modalidádes adoptadas por la bastarda en las diversas áreas geográficas europeas deberán consultarse además los facsímiles reproducidos en E. CROUS - J. KIRCHNER, Die gotischen Schrittarten, KIRCHNER, I. Scriptura Gothica Libraria, y O. MAZAL, Buchkunst der Gotik. También puede estudiarse el uso documental de las bastardas en: Die Fürstenkanzlei des Mittelalters. Anfänge Welticher und geistlicher Zentralverwaltung in Bayern. Ausstellung des Bayerischen Hauptstaatsarchivs anlässlich des VI. Internationalen Kongresses für Diplomatik. München, 25. Oktober-18. Dezember, 1983. München, 1983. Una completa visión de los facsímiles existentes para el estudio de esta escritura se podrá localizar on BOYLE, L E Modieval Latin Palaeography. A bibliographical introduction. Toronto, University Press, 1984, pp. 1975 y ss. Una lista detallada de todos los manuales de paleografía que proporcionan información sobre este tipo gráfico puede consultarse en GIMENO BLAY, F. M., La Escritura Gotica, pp. 105-106.

(19) Una amplia información sobre este tema podrá localizarse en CANELLAS, A. TRENCHS, J., Cancilleria y Cultura: La cultura de los escribanos y notarios de la Corona de Aragón (1344-1479) (en prensa) y especialmente el capítulo titulado: «Los humanistas de la corte napolitana".

(20) Cfr. ULLMAN, B. L. The Origin and Development of Humanistic Script. Roma, Edizioni di Storia e Letteratura, 1960. Una amplia lista de la bibliografia existente sobre la escritura humanística podrá localizarse en P. SUPINO MARTINI, Nota Bibliográfica, publicada como apéndice de G. CENCETTI, Paleografía Latina, Roma, Jouvence, 1978; pp. 188190.

(21) Para el estudio de la humanistica en la Península lbérica sólo disponemos de las noticias facilitadas por los manuales clásicos de la paleografía española. Por ello sólo recogemos el último aparecido: MILLARES CARLO, A. Tratado de Paleografía Española. Con la colaboración de J. M. RUIZ ASENCIO. 3." ed. Madrid, Espasa Calpe, 1983.

(22) Ctr. ARIENZO, L. d', Alcune considerazioni sul passaggio dalla scrittura gotica all'umanistica nella produzione documentaria catalana dei secoli XIV e XV. STUDI DI PA- 
LEOGRAFIA E DIPLOMATICA. Padova, pp. : GIMENO BLAY, F. M., La escritura gótica en el País Valenciano, comentario al facsímil XVII; y GIMENO. F. - TRENCH, J., La escritura medieval en la Corona de Aragón.

(23) Sobre los problemas textuales cfr. I/ libro e il testo. Atti del Convegno Internazionale. Urbino 20-23 settembre 1982. Urbino, Universita degli Studi, 1984. Respecto a los problemas de lectura y lectores en la Edad Media y Renacimiento cfr., respectivamente, CAVALLO, G. (ed.) Libri e lettori nel medioevo, Guida storica e critica. Bari, Universale Laterza, 1983; y PETHUCCI, A. (ed.). Libri, scrittura e pubblico nel Rinascimento. Guida storica e critica. Bari, Universale Laterza, 1979.

(24) Desde hace algún tiempo estamos preocupados, tal vez con el condicionante de la Historia de las Mentalidades, por introducirnos en el estudio del comportamiento de la población ante la cultura escrita y más concretamente ante sus manifestaciones públicas. Algunas tímidas hipótesis lanzaba uno de nosotros en la comunicación presentada al coloquio "Status-Professione-Scrittura", celebrado en Perugia en septiembre 1985 con el título: Los analfabetos y la Administración. Notas sobre sus relaciones a través de la escritura, cuyas actas se publicarán en las «NOTIZIE del Seminario Permanente de Alfabetismo e Cultura Scrittan, vid. nota 48 de este mismo trabajo.

Como modelos de referencia para realizar el estudio de la IMAGEN que la cultura escrita representó en las sociedades bajomedievales nos han sido de suma utilidad los trabajos de PETRUCCI, A., La scrittura tra ideologia e rappresentazione. STORIA DELL'ARTE ITALIANA. Parte terza: “Situazioni, momenti, indagini». Volume secondo: «Grafica e immagine; I, Scrittura, Miniatura, Disegnon. Torino, Einaudi, 1980; pp. 5-123, donde se puede encontrar una amplia bibliografla; A. PETRUCCl, / libro manoscritto. LETTERATURA ITALIANA, 2: uProduzione e consumom. Torino, Einaudi, 1983, pp. 499-524 y especialmente la parte final dedicada a trazar un percorso iconografico intorno alle immagini del libro nella tradizione artistica italiana dal XIV secolo ad oggi... También nos resultó de sumo interés de A. PETRUCCl, Bozza di un progetto di una mostra sul tema: scrittura e popolo nella Roma Barocca (1585-1721). ALFABETISMO E CULTURA SCRITTA. Seminario Permanente. Notizie, dicembre, $1980 ;$ p. 17-19 y el catálogo de la Mostra que citamos en la nota número 7 de este trabajo. Fueron interesantes también los catálogos de las exposiciones celebrados con motivo del XV Centenario de S. Benito en Italia (Montecassino e la cultura scritta. XV centenario de la nascita di S. Benedetto. Roma, (s.a.)) y en España (La comunicación en los monasterios medievales. XV centenario de San Benito. Monasterio de santo Domingo de Silos, julio-agosto, 1980).

Los trabajos de G. CAVALLO, Le iscrizioni di Ravenna dei secoli VI-VIII. Tracce per un studio grafico-culturale. XXXI CORSO DI CULTURA SULL'ARTE RAVENNATE E BIZANTINA, Ravenna 7/14 aprile, 1984; pp. 109-136; y de G. C. SUSINI, Epigrafia Romana, Roma, Jouvence, 1972, también nos proporcionaron ideas interesantes para el desarrollo del presente trabajo. La investigación bibliográfica que hemos llevado a cabo sobre este tema nos ha hecho conocer otros estudios, sólo por referencia, de gran interés para el análisis que nos proponemos efectuar con nuestros compañeros, al estudiar las representaciones iconográficas del libro y de la escritura en los retablos bajomedievales valencianos. Nos referimos a los trabajos: Schrift als Ornament, publicado en «Buch und Schrift» en ealahrbuch des Deutschen Vereins für Buchweuen und Schriftum» II (1928); La scrittura: funzioni e ideologie, a cura di G. R. CARDONA. La RICERCA FOLCLORICA, 1982; MASSIN, R. La lettre et l'image, la figuration dans l'alphabet latin du $8^{\mathrm{e}}$ siecle à nos jours. Paris, Gallimard, 1970 y DRAGONETTI, La viex de la lettre au Moyen-Age. Paris, Le Seuil, 1980.

Muchas han sido las representaciones de la cultura escrita, escritura y libro, que hemos localizado en colecciones de pintura y sobre todo en miniaturas. De todas ellas queremos destacar una representación de la FILOSOFIA procedente de un manuscrito italiano de la Toscana o Sur de Italia 1343-1344, donde la mujer que representa a la sabiduría porta como atributos un gran número de libros (Cfr. MAZAL, O. Buchkunst der Gotik, facs 67, «Huldigungsgedicht an König Rober v. Neapel).

(25) Cfr. SUSINI, G. C. Epigratia romana, p. 143.

(26) Cfr. BATTELLI, G. Lezioni di Paleografia. $3^{a}$ ed. Citta del Vaticano, 1949; p. 227.

(27) Cfr. SCHMITT, J. C. Présentation, al volumen titulado Prêcher d'Exemples. Récits de prédicateurs du Moyen âge, présenté par ...; Paris, 1985, p. 9. 
(28) Cfr. PETRUCCI, A., La scrittura tra ideologia e rappresentazione. uStoria dell'Arte Italianaw. Parte terza: situazioni, momenti, indaginim. Volume secondo: «Grafica e immagine; I, Scrittura, miniatura e Disegnon; pp. 5-123, y especialmente las pp. 7, 10 y 11.

(29) Cfr. HAENENS, A. d', Ecrire, utiliser et conserver des textes, p. 229.

(30) Cfr. RIBAUCOURT, C. L'Alphabet des récits: pour parler de femmes, en "Prêcher d'Exemples: Récits de predicateurs du Moyen Age». Paris, 1985; pp. 107-120.

(31) Cfr. LLULL, R. Art abreujada de predicació, a cura de C. WITTLIN. Barcelona, Ed. Mall, 1982; pp. 31-32.

(32) Cfr. CHEVALIER, J. (dir.) Dictionnaire des symboles. Mythes, Reves, Coutumes, Gestes, Formes, Figures, Couleurs, Nombres, sous la direction ..., Robert Laffont, 1980; $p$. 317.

(33) Cfr. HAENENS, A. D', Écrire, utiliser et conserver des textes, p. 237.

(34) Cfr. SUSINI, G. C. Epigrafia romana, p. 156.

(35) Cfr. HAENENS, A. d', Ecrire, utiliser et conserver des textes, p. 242.

(36) Cfr. PETRUCCI, A., La scrittura tra ideologia e rappresentazione, p. 14.

(37) Cfr. CHEVALIER, J. (dir.), Dictionnaire des symboles, p. 465.

(38) Segunda a Timoteo, 3, 14-17.

(39) Cfr. FERRANDO ROIG, J., Iconogratia de los santos. Barcelona, 1950, p. 280.

(40) Cfr. CHEVALIER, J. (dir.), Dictionnaire des symboles, p. 465.

(41) Cfr. PETRUCCI, A., // libro manoscritto, en "Letteratura Italiana II: Produzione e Consumo». Torino, Einaudi, 1983; vid. comentario a la reproducción n. ${ }^{\circ} 14$.

(42) Cfr. CARDONA, G. R., Sull'Etnografia della scrittura, p. 215.

(43) Citado por HAMMAN, A. G., L'épopée du livre. Du scribe à l'impremerie. Paris, 1985 ; p. 101.

(44) Este canal distributivo de la información es el propuesto por G. C. SUSINI en su Epigrafia romana, p. 156.

(45) Sobre la función que desempeñó la imaginería como activadora de la memoria véase RUIZ DOMENEC, J. E., La memoria de los feudales, pp. 13-14.

(46) Cfr. HAENENS, A. d', Ecrire, utiliser et conserver des textes, p. 230.

(47) Cfr. CHEVALIER, J. (dir.), Dictionnaire des symboles, p. 316.

(48) Cfr. CHEVALIER, J. (dir.), Dictionnaire des symboles, p. 316

(48) Siguiendo esta línea en el departamento de Paleografia de la Universidad de Valencia se han realizado los siguientes trabajos: TRENCHS ODENA, J, Entorn de la algnorantia Litterarum "n documents dels segles $X-X I$, «Miscel-lania ARAMON i SERRA en el seu setantè aniversari", III, Barcelona, 1983; pp. 573-582; GIMENO BLAY, F. M., La escritura en la Cartuja (Análisis diacrónico a través de las Constituciones). SAITABI, XXXIl (1983), pp. 5-17; GIMENO BLAY, F. M., La escritura en la diócesis de Segorbe. Una aproximación al estudio del alfabetismo y la cultura escrita en el Alto Palencia (1383-1458). Tesis doctoral inédita. Valencia, 1984. De ella se publicó un extracto con el mismo título en el «Boletín del Centro de Estudios del Alto Palancia” 1-2 (1984) pp. 49-60.

GIMENO BLAY, F. M., Gli analfabeti e l'amministrazione. Note sui loro rapporti attraverso la scrittura. ALFABETISMO E CULTURA SCRITTA. Seminario Permanente, Notizie, $n .^{\circ} 7$ (en prensa).

CRUSELLES GOMEZ, J. J.: La familia de Antoni Lopic, notario de la ciudad de Valencia (1433-1493). Promoción social de un profesional de la escritura. Tesis de licenciatura inédita. Valencia, 1985; MANDINGORRA LLAVATA, M. L., La escritura al servicio de la Administración municipal. La acumulación gráfica en los hospitales valencianos (1400-1509). Tesis de licenciatura inédita. Valencia, 1985; FERRER GIMENO, M. ${ }^{a}$ R., La lectura en Valencia a finales del XV. La Biblioteca del canónigo Maties Mercader ( ${ }^{1489}$ ). Tesis de licenciatura inédita. Valencia, 1985. En todos ellos se puede encontrar una amplia bibliografia y materiales para el análisis que hemos propuesto. Actualmente estamos preparando con $\mathrm{M}$. L. MANDINGORRA un trabajo titulado Competencia y educación gráfica en la Valencia del 500: el libro de albaranes del convento del Carmen (1517-1538). 